\title{
Research on Quality Evaluation Mechanism of Collaborative Talent Cultivation of Applied Colleges and Enterprises
}

\author{
QU Yanpeng ${ }^{1 *}$, YANG Yanqiu ${ }^{1}$, Li Heng ${ }^{2}$, Xia Riwei ${ }^{3}$
}

\author{
${ }^{1}$ College of Animal Science and Veterinary Medicine, HeiLongJiang BaYi Agricultural University, Daqing 163319, China \\ ${ }^{2}$ College of Animal Science and Technology, Northeast Agricultural University, Haerbin 150000, China \\ ${ }^{3}$ College of Veterinary Medicine, Yang Zhou University, Yangzhou 22500, China
}

DOI: $10.36347 /$ sjavs.2020.v07i07.003

| Received: 02.07.2020 | Accepted: 09.07.2020 | Published: 16.07.2020

*Corresponding author: QU Yanpeng

Abstract

Review Article

This paper analyzes the existing problems of indicators, methods, subjects and objects, and feedback mechanisms in the quality evaluation mechanism of the school-enterprise collaborative talent training by analyzing the schoolenterprise collaborative talent training model. The "532" evaluation model strengthens the application of the quality evaluation mechanism for the application of university-enterprise collaborative talent training quality, and further improves the quality of school-enterprise collaborative talent training.

Keywords: school-enterprise collaborative; evaluation mechanism; application-oriented universities; talent training quality.

Copyright @ 2020: This is an open-access article distributed under the terms of the Creative Commons Attribution license which permits unrestricted use, distribution, and reproduction in any medium for non-commercial use (NonCommercial, or CC-BY-NC) provided the original author and source are credited.

\section{INTRODUCTION}

Applied colleges and universities are to train talents with compound application and technical skills. Industry-education integration refers to a kind of cooperative activities, relationships and mechanisms established by enterprises and universities to share resources, complement each other's strengths and connect demands [1]. In 2017, the General Office of the State Council issued "Several Opinions on Deepening the Integration of Industry and Education", emphasizing that deepening the integration of industry and education is an urgent requirement for the current structural reform on the human resources supply side. Collaborative education emphasizes all-round and multi-level collaboration and integration among talents in universities, government, and enterprises. Collaborative education is suitable for the development path of talent training in application-oriented universities, and the collaborative education model has a crucial role in improving the quality of talent training in application-oriented universities [2].

On the basis of industry-university-research cooperation, the United States has launched a cooperative practice education model [3]. This model is oriented to social needs, and enterprises are deeply involved in the process of talent training. In the system, collaborative education is a necessary part of talent training, and the system and coordination of the cooperative education system is emphasized [4, 5]. In the UK, the "sandwich" education model is used to develop collaborative education. The policy encourages and supports the connection between technology companies and universities[6], accepts students who are studying to participate in internship training on vacation, and counts internship performance as credits as part of the required credits[7]. At present, some wellknown high-corrections in the UK are experimenting with "shared education" as an innovation of collaborative education model [8]. Germany adopts "dual system education", especially for science and engineering students, who need to go to enterprises to accept modern apprenticeship for practical learning [9]. Japan adopts the "official-industry-academic" integrated collaborative training model. The distinctive feature of this model is that it focuses on the intermediary role of the Japanese government at all levels [10]. With the vigorous promotion of the government, it formulates a perfect system to ensure personnel training and industrial policies Fit together to ensure the goal orientation of collaborative training of talents. In addition, Israel, Canada and other countries have also implemented corresponding exploration and practice, basically adopting policies to encourage and strengthen collaborative education between universities and enterprises [11]. For application-oriented universities, the integration of industry and education and collaborative education are effective ways to train application-oriented talents [12] and the only way [13]. 
However, because the government, universities, and enterprises are subjects with different demands and goals [14], this may result in unequal power and responsibility and inconsistent goals in the collaborative process, resulting in the subject's unwillingness, insufficient motivation, and insufficient investment in collaborative education, poor coordination, etc. What kind of synergistic approach is adopted to coordinate the interests of all parties to ensure the quality of school-enterprise collaborative talent training, the relevant evaluation mechanism is not deep enough [15].

\section{Problems Existing in the Quality Evaluation Mechanism of Existing School-Enterprise Collaborative Talent Cultivation}

A variety of school-enterprise collaborative education models have emerged between universities and enterprises, but generally speaking, the problems are unidirectional motivation, emphasizing form than content, and lacking of supervision. Very little in-depth cooperation in top-level design and connotation construction are carried out. Studies have shown that some colleges and enterprises only require a more general determination of how many hours of teaching tasks, and lack a scientific and reasonably operable quality evaluation mechanism, which makes it impossible to clarify responsibilities for quality problems [16].

First, the quality evaluation indicators of the school-enterprise collaborative talent training are not perfect. The existing collaborative education quality evaluation indicators are mainly based on students 'assessment results, emphasizing the teaching evaluation of theoretical knowledge, and weakening the effective evaluation of students' actual hands-on ability.

Second, the method of quality evaluation of school-enterprise collaborative talent training is incomplete and unscientific. Existing collaborative education quality evaluation mainly focuses on the result evaluation of student training quality, and weakens the process evaluation of personnel training in the process of school-enterprise cooperation.

Third, the main body and object of the quality evaluation of school-enterprise collaborative talent training are incomplete: the current quality evaluation of collaborative education is mainly formulated by universities, and the school is the main body of the evaluation during the implementation of the evaluation, ignoring the evaluation of the enterprise and the enterprise's employers and student parties ; the object of evaluation mainly focuses on the evaluation of students in school, ignoring the evaluation of the quality and ability of students in work positions after leaving the school.
Fourth, School-enterprise collaborative talent training quality evaluation results lack effective feedback application mechanism: the results of the current quality evaluation of collaborative education are mainly used to evaluate the annual performance of school-enterprise performance, but the evaluation results cannot be used for the talent training process Diagnosis and improvement, which is not conducive to the improvement of the quality of collaborative education between schools and enterprises, but also greatly reduces the value of collaborative education quality evaluation work $[17,18]$.

Constructing an Appraisal Model of the Quality of the Cooperative Talent Cultivation in Universities and Enterprises

\section{Constructing the Skill Training Model of Integration of Production and Education}

The integration of industry and education refers to the integration of industry and education, interaction between schools and enterprises, and the deep integration of education and teaching processes [19]. The research team relies on students in the direction of pet doctors specializing in animal medicine, selects the school-enterprise cooperative pet diagnosis and treatment enterprise, extracts typical work tasks, builds a curriculum system of production and education integration, and relies on the school's teaching factory to give full play to the advantages of school-enterprise cooperation, constructing five training skills including theoretical skill training, operation skill training, professional skill training, comprehensive skill training, and internship training are. Through the training of the five links, the students' professional abilities can be improved step by step, and the company's job skills required by employees can be met. Theoretical skills training. Through the teaching of the school classroom and the "school-enterprise cooperation class" course knowledge, students complete the accumulation of basic theoretical knowledge of pet diagnosis and treatment such as animal physiology, animal biochemistry, clinical diagnostics, toxicology, imaging, nutrition. Operation skills training. Students complete the operation skills training of pet drug injection, reading prescriptions, fixing pets, temperature measurement, and disposal room skills. Professional skills training. Students complete professional skills training such as pet consultation, pet disease diagnosis, pet disease drug treatment, disease laboratory diagnosis, surgical treatment and post-treatment. They have disease diagnosis capabilities and can correctly treat pet diseases. Comprehensive skill training. Students accept work dispatched by enterprises to complete diagnosis and treatment of related diseases in pet departments, complete pet disease treatment, pet disease laboratory diagnosis, pet grooming and other positions. Post practice. Adopt personnel rotation and post rolling. 


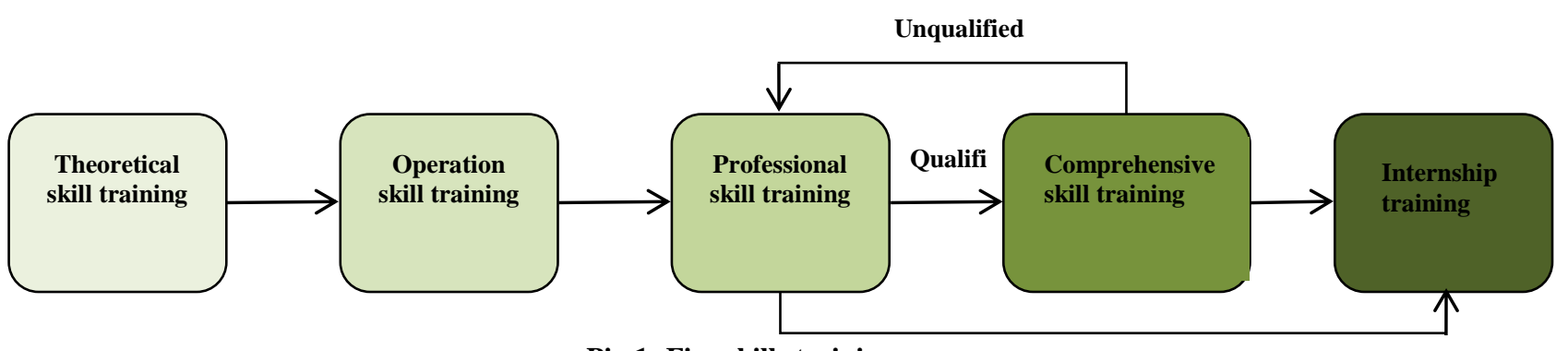

Pic-1: Five skills training process

\section{Establish "532" Evaluation Mode}

Infiltrate the entire evaluation model into the "five processes" of theoretical skill training, operation skill training, professional skill training, comprehensive skill training and post practice, and implement the five processes through the "tripartite" of schools, enterprises and governments Conduct process quality and result quality evaluation. After the students graduate, the school will follow up the investigation of the graduates, listen to the feedback from the employers, and dynamically adjust the assessment content to adapt to the changes in the post capacity of the enterprise to realize the whole process of teaching practice evaluation.

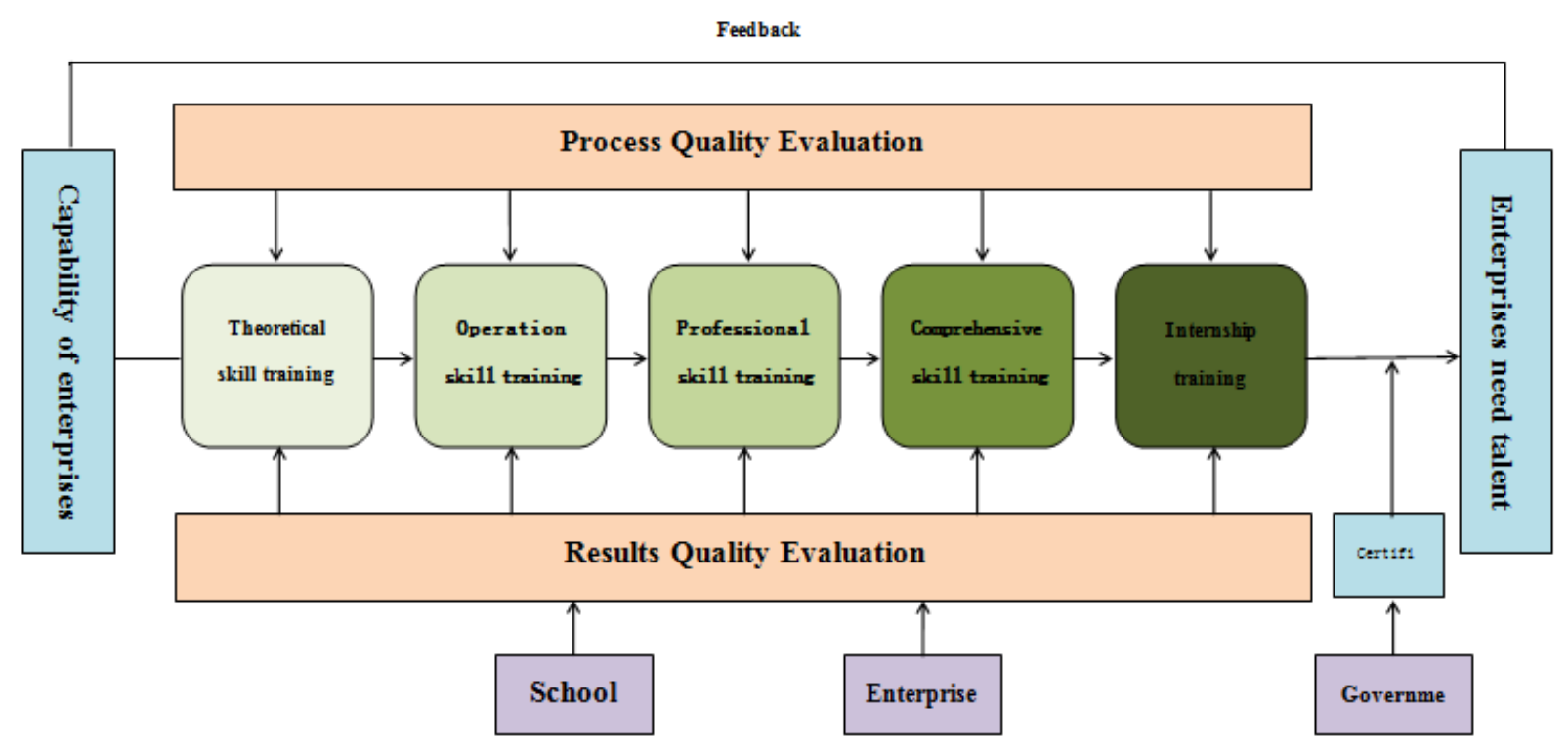

Pic-2: "Three aspects" Evaluation
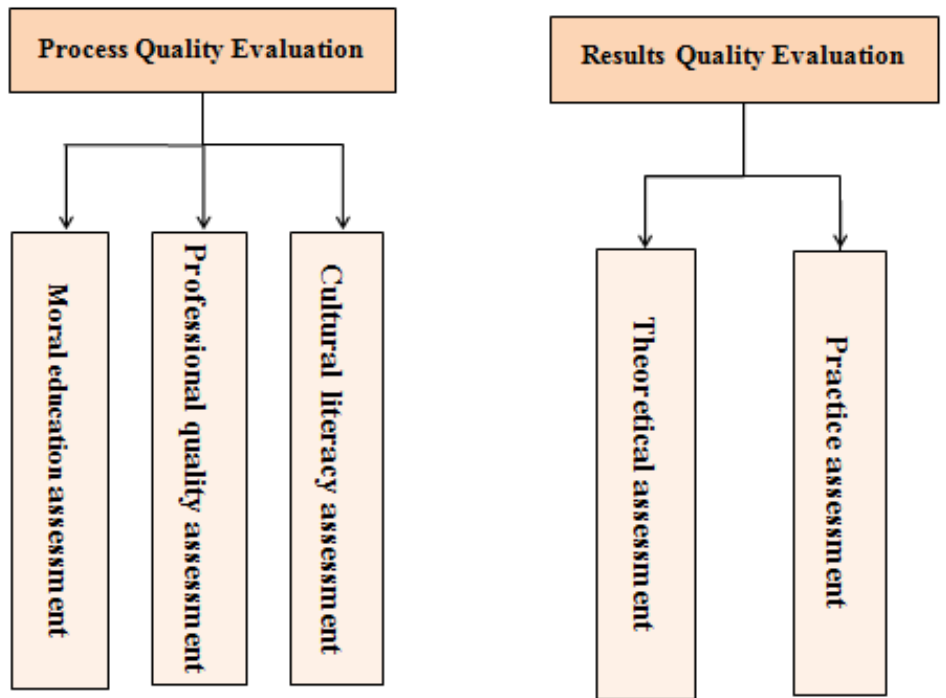

Pic-3: "Two Quality" Evaluation and Assessment Content 
The main contents of the evaluation: first, the evaluation of basic resource quality: refers to the basic resource environment at the school and enterprise levels before the start of the school-enterprise cooperation talent training project. The second is the quality evaluation of the design mechanism: it refers to the idea of cooperation between schools and enterprises and the hardware conditions prepared for the implementation of cooperation. The third is the implementation process quality evaluation: refers to the aspects of teaching quality, project development level, innovation achievement level, skill competition results, and students obtaining professional skills certificates during the implementation of a school-enterprise cooperation talent training project. Master the level and the level of practical ability, focusing on evaluating students' practical ability. Fourth, the quality evaluation of results: refers to "employment quality", which mainly includes quality factors such as the employment matching rate, salary level, employment competitiveness, and career development level of students.

\section{Strengthen the Application of Quality Evaluation Mechanism of School-Enterprise Collaborative Talent Cultivation}

The fundamental purpose of constructing the quality evaluation mechanism of school-enterprise collaborative talent training is to improve the effectiveness of school-enterprise cooperation, and to improve the quality of applied university-enterprise collaborative education. The application of quality evaluation results plays a very important role in improving the quality of educating people in applied universities. The implementation of "combination of evaluation and construction" focuses on the diagnosis and improvement of the quality of education. One is the implementation of quality diagnosis: the introduction of big data analysis technology, based on the analysis of the results of the evaluation of the quality of talent training by applied universities and enterprises, and timely diagnosis and discovery of the key factors that affect the quality of talent training. The second is to implement improvement measures: on the basis of determining the key elements of talent training quality, adjust and optimize the content and methods of schoolenterprise cooperative talent training, with a view to improving the quality of talent training. The third is to insist on continuous improvement: continuous iteration of diagnosis and improvement of talent training quality, and constantly discover and solve problems that affect the quality of collaborative talent training between schools and enterprises [20].

\section{CONCLUSION}

Schools and enterprises cooperate to educate people, complement and share superior resources, and form a strong cooperation situation. The advantage of colleges and universities is that professional teachers have high theoretical level, strong teaching ability, but weak practical ability, which is out of sync with the mainstream technology development in the industry; enterprises have engineers with rich practical experience and mainstream technology resources in the industry. Through school-enterprise cooperation, resources can be complemented and shared effectively, and the quality of talent training can be improved.

Focusing on the professional characteristics of applied colleges and universities, formulate a unique and innovative school-enterprise cooperation talent training plan. The school-enterprise collaborative talent training has a wide range of contents, which can achieve professional co-construction, and sharing of teaching resources. Based on the characteristics of talent training and the characteristics of regional economic development, application-oriented colleges and universities should choose the content and mode of collaborative talent training that suits their own development. Under the premise of clarifying the rights and obligations of both schools and enterprises, fully embody the purpose of mutual benefit and win-win, and formulate a scientific and reasonable school-enterprise collaborative talent training plan.

Focusing on "employment quality orientation", a quality evaluation mechanism for the cooperation between schools and enterprises that reflects the entire process and elements of talent training is built. The quality requirements of school-enterprise collaborative talent training need to be further decomposed into the entire process of talent training. It is necessary to make full use of the full factor resources of both schools and enterprises, and adhere to the combination of process and result evaluation, theory and practice, and internal and external evaluation. The principle fully reflects the comprehensive and scientific nature of quality evaluation.

Carry out the concept of "promoting construction with evaluation" and focusing on construction. Integrate the evaluation of schoolenterprise collaborative talent training quality with the diagnosis and improvement of talent training quality, and communicate and feedback the evaluation results, especially the process evaluation results, in a timely manner to rectify the problems found, so as to improve talent The training process continuously improves the quality of personnel training.

\section{REFERENCES}

1. Weibing Tang, Wen Hui, Jianping Peng. Constructi on of collaborative education mechanism under the concept of "integration of industry and education" [ J]. China Higher Education. 2018(08):14-16.

2. De Hei MS, Strijbos JW, Sjoer E, Admiraal W. Col laborative learning in higher education: lecturers' $p$ ractices and beliefs. Research Papers in Education. 2015 Mar 15;30(2):232-47. 
3. Hudson JN, Croker A. Educating for collaborative practice: an interpretation of current achievements and thoughts for future directions. Medical educati on. 2018 Jan;52(1):114-24.

4. Szteinberg G, Balicki S, Banks G, Clinchot M, Cull ipher S, Huie R, Lambertz J, Lewis R, Ngai C, Wei nrich M, Talanquer V. Collaborative professional d evelopment in chemistry education research: bridgi ng the gap between research and practice. Journal o f Chemical Education. 2014 Sep 9;91(9):1401-8.

5. Vest C. Pursing the Endless Frontier; Essays on MI $\mathrm{T}$ and Role of Research University.2004.

6. Zhu Jian, Liu Ying. A Study on the Innovation of th e Cultivation Mechanism of Doctoral Students of $S$ ocial Sciences in the UK-Taking the Scottish $\mathrm{Gr}$ aduate School of Social Sciences as an Example [J ]. Journal of National Academy of Education Admi nistration. 2017(07):80-88.

7. Sklar DP. Interprofessional Education and Collabor ative Practice-If Not Now, When?. Academic Me dicine. 2016; 91(6): 747-749.

8. Callagher T. Shared education in Northem lreland:s chool ollaboration in divided societies [J].Oxford R eview of Education. 2016,42(3):1-14.

9. Yahua Kang. The Enlightenment of German Univer sity of Applied Sciences on the Transformation of $N$ ewly Established Undergraduate Colleges in China [J]. Journal of Changzhou Institute of Information Technology. 2015,14(05):1-4.

10. Caiyun Zhang, Bi Cheng. Israel Innovative Talent Training Strategy and Its Enlightenment [J] .Chine se Journal of Education. 2013(12):6-10.

11. Zuchao Li, Liqin Zhang. A Comparative Analysis of the Paths for Collaborative Training of Top-notc h Innovative Talents by the United States, Japan, In dustry, University and Research Institute [J] .Mode rn University Education. 2013(03):41-47.

12. Wu Jun, Haijiao Wang. Reform and Practice of the Talent Training Model of Independent Colleges un der the Background of Industry-Education Integrati on_-Taking Zhejiang University of Finance and
Economics as an Example [J] .Special Zone Econo my. 2018(09):69-72.

13. Weixia Chen. Research on the Collaborative Educ ation Management Mechanism of Applied Universit $y-$ Based on the Perspective of Industry-Educati on Integration [J]. Chinese Vocational and Technic al Education. 2017(32):42-47.

14. Yabing Du, Chu Yu. Problems and Countermeasur es in the Integration of Industry and Education in $L$ ocal Undergraduate Colleges [J] .Teaching and Ed ucating (Higher Education Forum). 2018(18):12-1 3.

15. Changzhi Chen. Deepening the integration of indus try and education Problems to be solved urgently $i$ $n$ school-enterprise cooperation-Excerpts from the speech at the 2018 Chinese Vocational Educati on Society Expert Committee Meeting [J]. Chinese Vocational and Technical Education. 2018(13):5-6.

16. Xiaogang Wang, Lihua Zhu, Weixiang Jiang. Rese arch on Quality Evaluation Mechanism of Talent $C$ ultivation in Higher Vocational Colleges Based on School-Enterprise Cooperation [J]. Education Mod ernization. 2018; (49):27-32.

17. Yimin Wen, Xinhe Yi, Wei Lin. Research on the $C$ onstruction of Comprehensive Evaluation Index Sys tem of School-Enterprise Cooperation from the Per spective of Stakeholders [J] .Research on Chinese Universities. 2015; (09):58-62.

18. Xianhai Pang. Construction of Testing and Evaluati on System of University Education Quality [J] .Chi nese Adult Education. 2018;(22):54-56.

19. Steeb DR, Overman RA, Sleath BL, Joyner PU. Gl obal experiential and didactic education opportuniti es at US colleges and schools of pharmacy. Americ an journal of pharmaceutical education. 2016 Feb 2 $5 ; 80(1)$.

20. Steeb DR, Overman RA, Sleath BL, Joyner PU. Gl obal experiential and didactic education opportuniti es at US colleges and schools of pharmacy. Americ an journal of pharmaceutical education. 2016 Feb 2 $5 ; 80(1)$. 